\title{
O DESEJO DA LIBERDADE E A PARTICIPAÇÃO DE HOMENS LIVRES POBRES E "DE COR" NA INDEPENDÊNCIA DO BRASIL
}

\begin{abstract}
RESUMO: A Independência do Brasil não fez parte da "lógica na tural" dos fatos, vinculada a uma crise do Sistema Colonial que colocava a Colônia versus a Metrópole Após o grito do I piranga, a imprensa e as autoridades, tanto em suas cartas pessoais como em suas correspondências de trabalho, tocavam no assunto de forma auidadosa. Tentavam convencer aqueles que eram simpatizantes da "causa do Brasil" de que a independência como separação política era uma realidade a ser mantida. Um dos motivos alegados eram rebeliões das ruas de cidades como o Rio de Janeiro. As insurreições da população "decor" da Cortenão foram apenas uma ameaça cons tante, erigiram-se em realidade pal pável nas fugas, nos ajuntamentos e nos tumultos, que não raro se transformaram em devassas e que pontilham a documentação da Polícia e do Ministério da Justiça. Os escravos elibertos participaram com igual intensidade da política do pás e dos movimentos ocorridos. Fizeram uma leitura própria das idéias sobre a independência como autonomia, sobre a liberdade e sobre a libertação do jugo da reescravização, tentando colocálas na prática em diferentes momentos.
\end{abstract}

Gladys Sabina Ribeiro*

Palavraschave Independência. Participação da população de cor. Liberdade Revoltas populares. Projeto político.

THE WISH FOR FREEDOM AND THE PARTICIPATION OF FREE, POOR, "COlORED" MEN IN THE INDEPENDENCE OF BRAZIL

ABST RACT: The Independence of Brazil was not the consequence of a crisis that logically lead to a confrontation between the Colony and the Metropolis. After the "shout of independence" ("Grito

* Departamento de História da Universidade Federal Fluminense (UFF). E-mail: gladysr@uol.com.br 
do I piranga"), press and authorities only evoked that matter, both in their personal and professional correspondence, in a very careful manner. Faced with the street riots in such dities as Rio de Janeiro and others, they tried to convince the advocates of the Brazilian cause that independence as a political separation was a reality to be maintained. More than frequent threats, the uprisings of the "colored" population in the Capital became a tangible reality of runaways, groupings and disturbances that frequently turned into official inquiries, as the Police and J ustice Department files clearly show. Both slaves and freemen actively took part in the country politics and all the events that marked the period. They tried to put into practice their own interpretations of the ideas of independence as autonomy; of freedom; and of the risks of going back to slavery.

Key words Independence Colored people's participation. Freedom. Popular riots. Political project.

etrópole versus Colônia, colono versus colonizador, crise do antigo Sistema Colonial versus prosperidade da Colônia, nativismo versus nacionalismo são bipolaridades que marcam as historiografias brasileira e portuguesa sobre o final do século XVIII e início do XIX. Essas mesmas oposições são, conseqüente mente, abordadas nas análises feitas pelos livros didáticos quando tra tam desse período.

Os trabalhos de Sérgio Buarque de Holanda, Maria Odila Leite da Silva Dias, Lenira Menezes Martinho, Riva Gorenstein e Alcir Lenharo trouxeram para o centro da cena explicativa do processo da independência os comerciantes e outros agentes desse processo. Relativizaram, então, a divulgada participação dos grandes proprie tários de terra e de escravos nesse processo, foco privilegiado de aná lise de autores que, como Caio Prado Júnior e Né son Werneck Sodré atribuíam a esses agentes e a seus interesses na manutenção do latifúndio, da escravidão e da monocultura a responsabilidade pelos acontecimentos que levaram ao ${ }^{7}$ de setembro. Embora fugissem da ênfase nas atitudes dos grandes personagens da história e cerrassem fileiras na formação do Brasil a partir das estruturas socioeconômicas e das relações de produção, acabavam dando a estes indivíduos pa pel destacado e responsabilidade final nos eventos por consideraremnos inevitáveis. Partiam do quadro de crise do Sistema Colonial ante as mudanças sofridas na economia mundial, alavancadas pela Revolução Industrial inglesa e pela expansão do liberalismo. Enfatizando o atraso das políticas mercantilista e absolutista portuguesas - que 
levariam às medidas dúbias e aparentemente contraditórias de D. J oão VI no período que viveu no Brasil -, marcavam posição em um economia colonial extremamente dependente da metrópole e de seus agentes, sendo a Colônia portuguesa apenas e exclusivamente objeto de exploração dentro do Pacto Colonial.

Seguindo os caminhos abertos pelo primeiro conjunto de autores, João Luiz Ribeiro Fragoso questionou a existência da chama da crise do Sistema Colonial na América portuguesa. Demonstrou que os negociantes de grosso trato, sediados na sua maioria na cidade do Rio de Janeiro, comandavam as transações comerciais no império luso-brasileiro desde pelo menos finais do século XVIII. Ricos e com tratos na África, Ásia e Europa, eram também chamados de homens de grossa aventura por possuírem muitos cabedais e se arriscarem no lucrativo negócio negreiro, que movimentava as balanças comerciais do Brasil para Portugal e que propiciava a formação de um mercado interno, já naquele momento. Por meio de políticas de seguros e de endividamentos, aumentavam suas fortunas e até agiam com certa liberdade com relação à Coroa, o que se acentuou com a vinda da Família Red, em 1808.

Para o período de 1790 a 1830, com base em sólida pesquisa, Fragoso comprovou que os negócios tocados desde o Brasil iam bem, obrigado. Estavam em tão boa saúde quanto a economia colonial, ao contrário das interpretações de crise e decadência, tradicionalmente vigentes nas historiografias brasileira e portuguesa. Aliás, esta sua interpretação teve coro com outra, feita por Valentim Alexandre do outro lado do Atlântico, o qual demonstrou que ao menos até a invasão napoleônica a economia portuguesa era próspera.

Dessa forma, partindo dos autores acima vale a pena apresentar uma breve reflexão sobre a Independência do Brasil, o entendimento da liberdade e/ou autonomia e a participação dos homens "de cor" nos acontecimentos do início dos anos da década de $1820 .{ }^{1}$ É preciso começar dizendo que, na época, $D$. Pedro, José Bonifácio e outros não lutavam especificamente pelo que depois passamos a de nominar independência do Brasil. Os grupos, ou "facções" políticas, existentes no Rio de Janeiro - e que pugnavam ao redor do constitucionalismo e do liberalismo portugueses -, eram unânimes nos bons propósitos de organização da Nação portuguesa ao redor de leis básicas e promotoras da liberdade do indivíduo. Tais qual a idéia de liberdade, as noções de igual dade e fraternidade eram complexas e estavam na pauta do dia, sempre reportadas às noções do direito na 
tural, que promovia uma rediscussão do pacto entre o rè e seus súditos e questionava as bases do Antigo Regime Filósofos franceses como Montesquieu, Rousseau, Voltaire, Diderot, e outros pensadores anglo-saxões, como Bentham, foram lidos e reinterpretados com sentidos diferentes dos dois lados do Atlântico. Dessa forma, a llus tração portuguesa forneceu as bases para a elaboração e o triunfo do movimento constitucional ista, ${ }^{2}$ reafirmando a necessidade de se re forçar a construção do império luso-brasileiro, projeto vislumbrado no século XVI e acalentado com desenho próprio desde finais do sé culo XVIII. ${ }^{3}$

A liberdade era o grande tema de discussão no espaço público, no início do século XIX, sobretudo com as medidas tomadas por D. João VI a partir do estabelecimento da Corte no Brasil. Remetida à sociedade, subordinava a igualdade somente àqueles que eram pares e que tinham, na igualdade diante da lè, um dos fatores que poderiam justificála, que garantiam a vida e a propriedade Nesse momento, em que estes dirétos passaram a ser considerados inalienávés e gera ram o constitucionalismo com base nas experiências francesa e norte americana, a classe dominante enraizada no Brasil começou a entender a liberdade como fator de igualdade total com Portugal. Em outras palavras, dentro do contexto do constitucionalismo e dos seus interesses econômicos, passaram a desejar que o então Reino do Brasil permanecesse autônomo e livre, em igualdade de condições e de direitos com a antiga Metrópole Os portugueses do Brasil e os de Portugal, irmãos de uma mesma fraternidade, complementar-seiam em rique za e grandeza Esta era a igualdade na fraternidade, respeitando a propriedade e tendo como pressuposto a liberdade entendida como autonomia Assim, não foi desde sempre que a independência foi querida como separação total de Portugal. No âmago do problema estava a autonomia política desejada, que dava direito a tomar medidas com base nas especificidades da América portuguesa, ou seja a partir das instituições aqui estabelecidas, posteriormente tranfferidas à revelia para Portugal, e dos interesses econômicos em jogo. Não podemos esque cer de que dentro desse panorama as decisões vitais para a economia do império português eram efetivamente comandadas pelos negociantes da praça do Rio de Janeiro. ${ }^{4}$ Foi ao redor destas questões que se deram os debates acalorados sobre direitos iguais entre irmãos da mes ma família - a luso-brasileira. Primeiramente, os deputados da Colônia americana, chamados de "brasileirros" nas cortes lisboetas, embora alguns fossem de naturalidade portuguesa, reivindicavam os mesmos 
direitos para os dois lados da Nação portuguesa Solicitavam o respejto à economia americana e a presenvação de direitos adquiridos. Contudo, gradativamente, a partir das recusas dos deputados chamados "portugueses" em reconhecer a autonomia, tal redamação evoluiu.

As cortes reiteradamente negavam-se a reconhecer o Brasil como igual. Teciam seus argumentos tendo como ponto de partida a idéia de que a unidade e a igual dade seriam promovidas tratando as regiões do Brasil como províncias, províncias iguais a tantas outras existentes em Portugal. Para os deputados "portugueses" os dois lados do Atlântico seriam um mesmo reino, com sede em Lisboa. Temiam, depois do sucesso da Revolução do Porto, em 1820, que novamente Portugal se visse dependente das decisões tomadas no Rio de Janeiro. Valentim Alexandre analisou os debates e as políticas adotadas pelas cortes lisboetas, relacionando-os sempre aos interesses do comércio. Para ele, existiam grupos de deputados que pugnavam defendendo os interesses econômicos de uns e de outros. Havia, assim, os "integracionistas", os que queriam ce der aos desejos de autonomia do Brasil, e, ainda, aqueles que que riam esmagálo com o envio de tropas, sobretudo para o Rio de Janeiro e para o Recife; fora, obviamente, os que mudavam de lado a cada pouco.

Os "integracionistas" eram a "facção" mais forte, ou pelo me nos a mais barulhenta. Entre eles estavam Fernandes Tomás, Xavier Monteiro, Gonçalves de Miranda, Soares Franco, Girão, Pessanha, Castro e Abreu, Margiochi, Agostinho José Freire, entre outros, todos duramente criticados nas páginas dos jornais cariocas no ano de 1822. Segundo proposta de Fernandes Tomás, no início de 1821, dever-seia estender ao Brasil a Constituição de Portugal. Para o solene constituinte, isso não era "opressão colonial" alguma porque fa ria desaparecer a diferenciação entre "europeus" e "americanos", podendo-se dispensar o uso da força, ou seja, o envio de tropas. O liberalismo vintista não concebia o Brasil como uma entidade autônoma; associava os descontentamentos brasileiros ao despotismo do Antigo Regime e à sua forma de administrar o território america no, ${ }^{5}$ circunscrevendo-os ao âmbito político. Ao restabelecer a sua hegemonia sobre o império, tudo voltaria à normalidade e as terras brasileiras seriam tratadas com igualdade, como qualquer outra província do Reino. ${ }^{6}$ Não aceitavam divergências a respeito dos princípios liberais que defendiam e queriam impô-los como os melhores para a Nação portuguesa. 
As aspirações de autonomia eram vistas como ilegítimas e conspiratórias. Foi o que ocorreu com a delegação de São Paulo, que tomou assento no Parlamento a 11/2/1822. Levou um projeto para "restabelecer os negócios políticos entre Brasil e Portuga".7 Nele, as duas partes da Monarquia ficariam "unidas para sempre", porém com administração, instituições e leis independentes. Prevendo a residência do soberano no Brasil ou em Portugal, de acordo com as circunstândias, sublinhava serem os tratados políticos comuns, contudo salvaguardava a possibilidade de cada país fazer tratados comerciais em separado, além de estabelecer de imediato "relações comerciais mutuamente vantajosas". Os parlamentares paulistas propunham a existência de dois reinos, em uma espécie de "federação", rejeitando exatamente a tese de ser o Brasil uma "província". A polêmica foi grande e os "integracionistas" lutaram por desautorizar a comissão formada para estudar os assuntos do Brasil, acabando por pedir punições para a Junta de São Paulo, em março de $1822 .{ }^{9}$ Capitaneados por Fernandes Tomás, defendiam que, se os brasileiros não se submetessem às cortes, deveriam se separar. Jogavam com essa possibilidade mais como hipótese ${ }^{10}$ no fundo alternativa indesejada. Baseevam a sua argumentação em uma espécie de "nacionalismo", no qual a "dignidade naciona" tinha grande peso, pois o objetivo seria preservar o "poder do soberano Congresso" e a hegemonia portuguesa no "Sistema Luso-Brasileiro". As perdas pela possível separação eram minimizadas por julgarem ter sido os lusitanos muito prejudicados a partir de $1808 .{ }^{11}$

Com essas posturas, aproximavam-se do "patriotismo mercantil" existente em Portugal, na época. Todavia, este relacionamento era bastante tenso. Por um lado, as propostas parlamentares tinham seus encantos para os negociantes da velha Metrópole previam a re tomada dos monopólios e consideravam o Brasil apenas mais uma província, para onde se poderia enviar tropas que defendessem as suas consignações no Nordeste, sobretudo em Pernambuco. ${ }^{12}$ Por outro, os "integracionistas" falavam quase sempre em separação para defesa da "dignidade naciona", havendo a possibilidade de provocar desas tradamente a "ruptura". I sso a burguesia mercantil metropolitana não poderia admitir nunca, uma vez que visava não somente a recuperar os monopólios, mas também a buscar mercados e novas fontes de acumulação de capital, imiscuindo-se no tráfico e no mercado bra sileiros. ${ }^{13}$

Finalmente, ante esta posição passaram os deputados e os jornais brasileiros a clamarem por uma Assembléia própria e uma 
Constituição espeć́fica para a América, a exemplo do que a Espanha, em determinada época da sua história, havia feito com as suas colônias. Contrariar estes quesitos significava para os "brasileiros" a recolonização; defendêlos, a independêndia Portanto, esta última era mais pensada como sendo sinônimo da liberdade - genérica - e da autonomia. Não queriam, necessariamente, criar um país liberto de la ços com Portugal. A independência foi um combate pela liberdade dentro da Nação portuguesa; não foi pensada e amadurecida como rompimento desde finais do século XVIII, a partir dos movimentos nativistas e de problemas ligados à famosa crise do Sistema Colonia. ${ }^{14}$ As ações foram sendo tomadas pelos "homens bons" a partir e dentro do contexto luso-brasileiro e europeu, e de acordo com seus interesses, sabedores que eram de que a Pátria era o lugar reservado para si, que se consideravam "patriotas" e que se reconheciam por nexos de propriedade e de privilégio, desejosos de afirmar a consolidação da unidade a partir do Sudeste do Brasil. Não sendo mais pos sível construir a Nação portuguesa, era preciso afirmar o centro no Rio de Janeiro, garantir o bom exerć́cio da liberdade e o seu corre to entendimento; proteger a "causa da liberdade", pouco tempo de pois transformada em "causa da Nação", e, ainda mais tarde, em "caur sa do Brasil". Na representação do espaço Brasil perpetuariam as suas conquistas - sobretudo a emancipação econômica - e evitariam a anarquia $\mathrm{Na}$ ótica de quem via o mundo pelas lentes americanas, e não portuguesas, só a permanência do príncipe regente (futuro $D$. Pedro I) seria capaz de congregar os interesses de alguns, representando-os como de todos. Assim foi feita a independência. Depois, é daro, de constatada a impossibilidade da união, em outras palavras, do projeto do império luso-brasileiro.

Portanto, o que estava em pauta era a discussão da liberdade entendida como autonomial. ${ }^{15}$ Eram estes os limites da discussão e para onde se direcionavam os debates nos jornais (como o Corréo do Rio de Janeiro e o Revérbero Constitudional Fluminense) e nos panfletos publicados na Corte fluminense e destinados ao convencimento da opinião pública; igualmente neste sentido convergiam as diferentes lutas do cotidiano, fossem elas na Assembléia Magna da Nação portuguesa ou em algum canto qualquer das cidades da velha M trópole e da promissora Terra Braślica, que naquele momento tinha no Rio de Janeiro a capital do vasto império lusitano. Evidentemente, a anarquia e a desordem, contrárias à liberdade, também mobilizavam a todos. Os impressos destilavam lições de 
liberalismo e disputavam o que seria melhor, se a soberania da $\mathrm{Na}$ ção ou a soberania popular.

Por isso, no processo da independência não cabe uma relação de causalidade, marcada por eventos exteriores aos processos internos da ex-Colônia, em ordem de sucessão direta A posteriori, colocaram-se os eventos enfileirados a partir da necessidade de se construir uma explicação convincente da independência; da necessidade de se dizer que o Brasil estava predestinado desde sempre, ou ao me nos desde o final do século XVIII, a ser próspero e autônomo, inde pendente como pás. É preciso esclarecer, juntamente com Valentim Alexandre, que a palavra "nacionalismo" não tinha curso ao longo da década de 1820; existiam apenas as palavras "nação" e "nacional". ${ }^{16}$

Vale também o lembrete de Eric Hobsbawn de que o conceito de Nação não tinha o mesmo significado no início e no fim do século XIX, sendo, dessa forma, bastante moderno. Para este último autor, a compreensão deste termo é dificultada por acharmos hodiernamente a identificação nacional "tão natural, fundamental e perma nente a ponto de preceder a história". ${ }^{17}$

Criou-se, então, a partir do evento consumado, uma "memória" dos fatos. Pouco a pouco, estabeleceu-se no 7 de setembro a data comemorativa do evento, que por muito tempo foi celebrado na data da coroação do imperador. Por que isso? Porque até 1824 os contemporâneos não tinham certeza se a separação total de Portugal, prodamada dois anos antes, havia realmente vingado. Não somente ha via planos de reconquista do Brasil como sabemos que o Tratado de Reconhecimento, assinado em 1825, saiu com muita dificuldade, graças às artimanhas dos pleni potenciários da Grã-Bretanha, que foram os efetivos negociadores da parte portuguesa ${ }^{18}$ Assim, coube aos contemporâneos e aos pósteros embasar a criação da Nação brasileira diferente da Nação portuguesa; buscar na história passada um na cionalismo que era anacrônico e que sequer existia como conceito e realidade; procurar tecer uma "memória" do pás fundada nos acontecimentos e no "heroísmo" de homens tidos como homens de visão, mártires e patriarcas da independência.

Resumindo, a consciência, dita nacional, foi construída a partir da atuação daqueles homens no seu tempo, das suas vivências, vale dizer, das circunstâncias políticas. As decisões foram tomadas no calor da hora. A obra da independência era sinônima de autonomia e respeito ao caminhos "brasileiros". Até o último momento se pensava poder obtêla dentro da própria Nação portuguesa. Que 
vantagens teriam os comerciantes do Rio de Janeiro em cortarem liames com Portugal e suas possessões? Além de serem eles, provavdmente, que custeariam a possível guerra contra Portugal, ficariam sem uma fatia expressiva do seu mercado, sem as fadilidades e as re galias da união dos dois reinos, que Ihes propiciava facilidades no ir-evir.

Dessa forma, a independência não era a "lógica natural" dos fatos. Nem era desejada há muito, tendo como antecedentes as inconfidências do final do século XVIII. Mesmo após o grito do I piranga, a imprensa e a sautoridades, em suas cartas pessoais e correspondências de trabalho, tocavam no assunto de forma cuidadosa. Por vezes ainda insistiam na importância do Reino Unido, ou criticavam e rememoravam os "desmandos" e "abusos" cometidos pelas cortes lisboetas, reafirmando o rompimento como a decisão acertada. Era um discurso pedagógico e de convencimento da opinião pública sobre a necessidade de a separação efetiva se consumar. Por último, ainda invocavam e publicavam as falas intransigentes de alguns deputados de Portugal nas cortes, isso muito depois do 7 de setembro e nos dois anos seguintes. Batiam na mesma teda dizendo que os velhos irmãos eram amigos-ursos, que a mãenação portuguesa era madrasta e que os constituintes portugueses cismavam em ler a liberdade com sinal contrário e negativo ao Brasil, diminuindo as nossas riquezas bem como Ihes tirando a importância Segundo os articulistas e redatores, os deputados "portugueses" preferiam unir-se à Espanha para fazerem frente à Europa, já que pensavam que o Brasil esvaziaria o Velho Continente de braços e sugaria a sua riqueza. Enfim, afirmavam que alguns constituintes portugueses, nos seus dis cursos, conduíam ser melhor deixar o Brasil entregue ao seu próprio destino, bem próximo àquele de São Domingos.

Logo, por meio do debate das cortes depreendemos que, para as classes dominantes dos dois lados do hemisfério, a liberdade significava o direito de conservação da propriedade, fosse em âmbito privado ou no ćrculo mais ampliado do comércio internacional e dos direitos sociais e políticos estabelecidos. Nesta igualdade da liberdade, reivindicada interpares ou internações, obviamente todos excluíam os escravos e libertos dos direitos de cidadãos. A liberdade, conceito genérico, descia ao concreto das ruas e ao cotidiano de todos. Devemos afirmar, como João J. Reis, que ninguém deve pensar que a discussão hipócrita sobre a liberdade, em um país majoritariamente escravista, não chegasse à população dita "de cor", fosse 
ela escrava ou forra Mais ainda, chegava a todos os homens pobres, fossem eles também brancos e despossuídos, como eram os imigrantes lusitanos que aqui chegavam em busca de oportunidades de conquistarem sua autonomia por meio do trabalho.

Era constante o medo da anarquia e das rebeliões das ruas. Em xeque, de forma mais imediata, a parcela dita negra da população. Os políticos "brasileiros" invocavam em sua defesa os disaursos da barbárie dos africanos e dos negros, em gerd, além dos episódios sangrentos que saaudiram São Domingos em finais do século XVIII enos primeiros anos do século XIX. Os deputados do lado português do Atlântico também utilizaram estes como constantes ameaças, que faziam eco na população branca "livre" e "bem-nascida". Na tribuna brandiam deixar o Brasil entregue à sua própria sorte, àquela da sanha dos negros.

Entretanto, tais vociferações não eram apenas um jogo teatral. Escravos e libertos também révindicavam a liberdade como autonomia jurídica e de ações. O movimento da população negra constituía-se sempre em ameaça à liberdade porque espelhava uma outra leitura desta, ou, melhor dizendo, deste desejo de autonomia, que se traduzia em práticas sociais e políticas diferenciadas.

Nos documentos do Primeiro Reinado e dos primeiros anos da Regência, a tropa e o povo aparecem atuando decisivamente em todos os episódios, da Independência à derrocada do imperador e aos movimentos políticos que se seguiram nas ruas da capital e das principais cidades do pás. Se a historiografia identificou líderes e "partidos" que fizeram seus nomes pelas atitudes tomadas naqueles dias, estes não estavam sozinhos. A população pobre e desvalida es tava sempre presente $\mathrm{N}$ ão como elemento figurante, mas conduzindo conjunta e efetivamente os fatos, gritando palavras de ordem em de fesa de uns e de outros, verdadeiros motes que incitavam atitudes diferenciadas de acordo com as circunstâncias, com o que estava em jogo e sendo pleiteado pelas variadas facções. Nas suas ações havia claramente uma finalidade a qual podemos, grosso modo, chamar de um projeto político. I gualmente a révindicação da liberdade, como uma forma de autonomia e de participação, estava presente Eram os "vivas", tão famosos e que não por acaso celebravam "a federação", "a república", "a causa da liberdade" ("independência", "liberdade de imprensa" e "liberdade do gênero humano"), "a monarquia como constitucional", "a Nação brasileira e os brasileiros", e outros tantos motes políticos, atribuindo-se inclusive a qualidade de "pessoas ca pazes e brasileiros constitucionais". ${ }^{19}$ 
Juntamente com o designado povo com " $\mathrm{p}$ " minúsculo, a documentação dá conta da participação da tropa A enunciação conjunta da tropa e do povo em si é bem típica das sociedades do Antigo Regime Mas, nesse caso, a junção ia além da enunciação. $\mathrm{Na}$ tropa havia batalhões de libertos e de escravos que, fugidos, viam na corporação uma oportunidade para conquistarem a autonomia. Aliás, essa era a mesma esperança de estrangeiros que aí se engajavam e dos portugueses pobres, que formavam suas fileiras menos qualifica das. Como podemos perceber, temos aí um foco de problemas, tra duzidos em disputas e rivalidades. Contudo, embora a análise da tropa, da sua composição, dos seus conflitos e dos significados da sua atuação nos eventos que antecederam e sucederam o 1822 seja importantíssima, não são estas as minhas preocupações nos limites deste artigo. Aqui considerare a tropa como parte importante do povo com letra " $p$ " minúscula, ${ }^{20}$ referindo-se tanto aos homens livres pobres como aos libertos e aos escravos. No dizer do século XIX, eram a massa, a turba, o populacho que atemorizava as autoridades. O povo foi o responsável maior por um conjunto de medidas de controle social no Estado nascente e preocupava aqueles que caminhavam por definir os contornos da Nação e do Estado brasileiros.

Muito provavelmente, para a maioria das pessoas que compunham o povo, ter liberdade traduziarse em atos pequenos do cotidiano que aos poucos foram tomando forma ao longo do século XIX e foram se constituindo em direitos maiores, vinculados à cidadania e ao que passamos a chamar de direitos civis, que no Bra sil somente foram regulamentados em 1917, muitos anos depois da abolição da escravidão. Para dizer de outro modo, observandose os seus atos podemos afirmar que o fundamental para aqueles homens pobres e despossuídos, "brancos" ou "de cor", era obter diferentes ganhos, que iam de aspectos pessoais até vantagens sociais, econômicas e políticas.

Para os escravos, sem dúvida o maior dos benefícios era a alforria, para a qual muitos - mas nem todos - lutavam com todas as forças ${ }^{21}$ Se por um lado não devemos perder do horizonte que homens livres pobres, escravos e forros não tinham necessariamente a mesma interpretação dos direitos naturais que sacramentavam os pactos elaborados pela classe dominante, por outro, devemos lembrar que o direito positivo que sacramentou a consolidação dos chamados direitos naturais em códigos, tornando-se fonte inequívoca de direitos e base para a construção de uma determinada ci- 
dadania, foi ganhando seu espaço ao longo do século XIX, derrotando outras formas de direito e de entendimento da política e da liberdade ${ }^{22}$ Portanto, vale dizer que derrotou outras propostas políticas que envolviam projetos variados para os destinos da $\mathrm{Na}$ ção. Certamente estes não passariam pela formulação das instituições sacramentadas pelo predomínio "saquarema", mas abririam espaços para outras leituras de liberdade e do pacto social, mais democráticos do que aquela pela via da propriedade. Podemos depreender esta possibilidade nos "vivas" e nas révindicações de varejo expressas nos atos perpetrados do dia-a-dia e registrados nos Códices de Polícia do Arquivo Nacional. Construir outros direitos sociais e outra concepção de cidadania não estava longe do que vis lumbravam. Não é esta justamente a época em que os direitos à vida e a peticionar - direitos "naturais" - são considerados inaliená veis? Se é certo que os homens livres pobres, libertos, escravos e "brancos" não possuíam conceitos políticos bebidos nos ideais liberais burgueses formulados do mesmo modo que a classe dominante o fazia, como bem lembrou Marcus de Carvalho, não pode mos ignorar que os interpretavam e que lutavam pelo que queriam com base nas suas experiências e concepções de mundo.

Partindo do grito do I piranga, as discussões nos jornais, dentro do governo, e, logo depois, na Assembléia Constituinte, passaram a se dar ao redor da afeição à nova terra, transmutada em "Pá tria" e "Nação brasileira"; ou seja, defendiam-se os interesses daqueles que passaram a ser chamados de cidadãos brasileiros mesmo que não tivessem nascido no Brasil. Excluíam-se totalmente os escravos e parcialmente os libertos; considerava-se cidadão ape nas aquela parte do Povo igual entre si e branca, ou seja, Povo com "P" maiúsculo, de preferência, cidadão ativo, que tinha, além dos direitos civis, os direitos políticos. ${ }^{23}$ Isso quer dizer que, na prática, muitos cidadãos também tinham seus direitos limitados e que muitos dos homens livres pobres e "brancos" eram igualmente desconsiderados. Vejamos.

Comecemos pelos homens livres pobres e "brancos". Por muito tempo eles foram desconsiderados pela historiografia, que julgava serem objeto de estudo privilegiado os despossuídos "de cor". Além disso, a mesma historiografia não considerava a possibilidade de um mercado de trabalho em formação nesse período, em que os "brancos" e "de cor" competiam entre si, formando linhas de exclusão e de segmentação que se acentuaram e perpetuaram até hoje 
O Revérbero Constitucional Fluminense de 6/8/1822 fazia uma clara distinção entre os portugueses ricos e os pobres, estes últimos considerados servos porque vinham tentar fortuna e enriquecer no Brasil:

O certo é, que a gente vil de Portugal, sem fortuna lá, escapando pela emigração da miserável condição de servos, evindo achar a opulência entre nós, são os nossos ini migos, equetodos os bem educados são nossos amigos, entretanto queos Brasileiros, queseagregam àqueles, são os des graçados destituídos de Luzes, edehonra, o que mostra assaz da qual das partes está a razão, ea justiça (Revérbero Constitudional Fluminense, $n$. 11, t. II)

Assim, os "servos" eram desprezados como pessoas, eram "vis" e miseráveis, imigravam fugindo da miséria e em busca de melhores oportunidades, de ganhos, de autonomia Por isso, não tinham compromisso com o Brasil e não eram adeptos da causa da liberdade, sendo identificados com os absolutistas e entusiastas do antigo governo. Enfim, em uma palavra: inimigos, não merecedores da confiança e de serem Brasileiros com " $B$ " maiúsculo. Identificavam-nos com os recolonizadores e com as idéias contrárias ao bem do Brasil, como eram os brasileiros com "b" minúsculo, que eram destituídos de Luzes e de razão.

Os Portugueses não conhecem seus verdadei ros interesses. Uma Política razoada, eprofunda, os convenceria dequeo engrandecimento do Brasil éo quegarante, ou a escora da sua estabilidade pendente, dequeneste, e não na ponta do péna Europa, deveestar a Metrópole da M onarquia, e de quesóo Império Brasilerro-Luso, tendo aqui otronco, podeconservar florescentesosbraços queramificamnasautras partesdo Gldbo. (itálico do próprio jornal) (RevérberoConstitudional Fluminense, n. 11, t. II)

Portanto, o melhor para o Brasil seria o Reino Unido, a liberdade vivida dentro da família ou Nação portuguesa Dessa forma, os braços do império floresceriam e ramificar-seiam pelo restante do globo, tanto em extensão quanto em indivíduos para o trabalho. Era com este espírito de união que se pretendia convocar uma As sembléia no Brasil, como já nos referimos acima, que respeitasse os interesses "Brasileiros", que seriam os melhores para todo o império. A legitimidade do império somente se daria com o Brasil e com os brasileiros guiando os passos da Nação portuguesa.

Este era o conteúdo de uma carta publicada em 25/5/1822 no Corréo do Rio de Janeiro. Seu autor discutia os critérios para o 
recenseamento da população com vistas ao estabelecimento de crité rios para a escolha do número de deputados para as cortes braślicas. Para ele, a denominação de cidadãos só deveria ser aplicada àquelas pessoas que estavam em pleno exercício dos direitos do homem, e, como tais, poderiam eleger e serem eleitas. Negava-se aos escravos a condição de cidadãos e a de estrangeiros, pois vinham da África ba nidos de sua pátria e pertenciam a quem os remiu. Mesmo quando eram "brasileiros", não deveriam ter direito algum, tais quais os servos portugueses. O que lhes caberia era o dever de obedecerem e de trabalharem. Tais como os estrangeiros desprovidos de Luzes e ra zão, encontravam-se apenas em "estado doméstico". Neste sentido, vale destacar que o articulista frisava que ninguém era senhor da pes soa do escravo, apenas de seu senviço. Isso ficava aliás bem evidente nas proibições de feri-los e matálos, como se fazia com os animais e com a preservação de toda e qualquer propriedade

Mas o escravo era uma propriedade um tanto ou quanto espe cial, levando a sua argumentação à dubiedade: ao mesmo tempo que não tinha direitos à cidadania, era considerado "brasileiro". Do mes mo modo que alguns portugueses, mesmos pobres e desprovidos dos direitos políticos, eram tidos como brasileiros por residirem no pás na época da Independência ou por terem aderido à causa nacional. Estas contradições não se davam à toa. Elas eras muito mais plauśveis do que possamos imaginar.

A insurreição da população "de cor" da cidade não era apenas uma ameaça constante, erigia-se em realidade palpável nas fugas, nos ajuntamentos e nos tumultos, que não raro se transformavam em de vassas e que pontilham a documentação da Polícia e do Ministério da Justiça. Lembremos que as notícias da Regeneração chegaram ao Rio de Janeiro em outubro de 1820 e as autoridades policiais preocuparam-se com o constante número de escravos armados com faca e transitando livremente pela cidade ${ }^{24} \mathrm{Em}$ outubro do ano seguinte, falavase de um "espírito de inquietação" entre as pessoas, "excitando os ânimos"; 25 ordenavam-se igualmente providências contra os "negros capoeiras", que "promoviam desordens nas ruas públicas", ${ }^{26}$ e contra os cativos, que passaram a usar máscaras, principalmente em festas, amedrontando o ministro de Estado dos Negócios do Reino. ${ }^{27}$

Finalmente, por conta desses episódios, o intendentegeral de Polícia, João I gnácio da Cunha que havia substituído Paulo Fernandes Viana, pediu demissão: não conseguiu conter a movimentação da po- 
pulação "de cor" nas ruas. Foi acusado pelo ministro de Estado da Guerra, Carlos Frederico de Caula, de agir de forma "branda", não cas tigando com açoites e outras punições públicas os escravos, libertos e capoeiras presos portando armas, também não mantinha presos indivíduos sem cul pa formada. Defendendo-se, João I gnácio lembrava o quão perigoso era a intromissão da Polícia e dos militares em efferas da Magistratura, além do mais, escravos deveriam ser punidos por seus senhores, ao passo que os livres, sendo "povo constituciona", tinham os seus direitos "públicos" garantidos porque eram "cidadãos". ${ }^{28}$

Em 1822, o secretário de Estado dos Negócios do Reino, José Bonifácio, vivia à espreita de notícias sobre os atos de rebeldia e as ameaças de revoltas do povo "de cor". ${ }^{29}$ No mês de fevereiro, restringiu a circulação de marujos pela cidade, acusando-os de perturbarem o sossego e a tranqüilidade públicos; estavam proibidos de andarem pelas ruas depois das 6 horas da tarde ${ }^{30} \mathrm{Em}$ meados de abril exigiu que o intendente examinasse com detal he umas cartas pegas com um "moleque", na rua da Carioca: elas falavam de um "Club de Malvados", ${ }^{31}$ que queria dizimar os "brancos" da mesma forma que Vieira Fazenda mencionou existir, na Regência, uma sociedade de capoeiras, conhecida por "gregoriana", que visava ao mes mo objetivo. Ainda no final desse mês, corriam boatos que padres incentivavam a insurreição da "população preta". Dizia-se que espaIhavam ter as cortes decretado a "liberdade da escravatura" e que S.A.R. ocultava tais papés, a fim de manter no cativeiro cidadãos agora livres. ${ }^{32}$ A 5 de agosto de 1822, em mais um ofício ao intendente-geral da Polícia, o fututo "Patrono da Independência" mandava que se atendesse à representação de Da Eugenia Maria da Incarnação (sic): “Em que expõe a necessidade de tomar o governo medidas vigorosas contra os que pretendem perturbar a tranqüilidade pública, seduzindo para isso os escravos com promessa de liberdade". ${ }^{33}$

Os jornais também davam testemunhos vivos da problemática do medo. O Corréo do Rio de Janeiro n. 118, de 4/9/1822, fazendo um extrato do Conáliador Lusitano, recordava uma discussão de alguns "Ilustres Membros" (sic) das cortes. Afirmavam, naquela oca sião, a necessidade de se mandar tropas para o Brasil, com a finalidade de submetêlo e fazer os "brasileiros" obedecerem à pátria-mãe Afinal estes já haviam dedarado guerra aos europeus e em Pernambuco gritavam: "Mata, que é branco". Dessa forma, acreditavam ser inevitável a guerra dos negros contra os brancos. Nas suas argumen- 
tações, o Império Negro (sic) teria sido um dos maiores do mundo e o Branco (sic) o teria dominado. Por isso, para conservação da propriedade daqueles que tinham direito, ou seja, dos cidadãos pacíficos, e para se manter a união da Monarquia portuguesa, era neces sário o envio da tropa portuguesa ao Brasil, para combater os facciosos. Portanto, os negros eram considerados uma facção dentre as muitas do período. Facção que era igual mente dividida entre si em nações, de onde se poderia tirar proveito instigando-se umas contra as outras. ${ }^{34}$

No Revérbero Constitucional Fluminense encontramos a reprodução de notícias de que os deputados portugueses na cortes lisboe tas jogavam com a ameaça permanente dos pardos e dos pretos como tentativa de intimidação. Com este expediente, tentavam barrar as reivindicações de igualdade de tratamento e de liberdade por parte dos deputados do Brasil. Entretanto, para os redatores desse jornal, tal ameaça de sublevação seria mais fatal a Portugal que ao Brasil.

Que desorientamento de idéas! Como se persuadem, que os escravos se levantarão contra os Senhores Brasileiros, sempremais brandos, esofre rão os Senhores dePortugal, sempremais crués? Não há uma lógica mais efarrapada! Eramelhor quecuidassem de seusFrades, edos seus privile giados: que tivessem sempre diante dos olhos, que aqueles saem na Espanha a combater cantando o Terço. Saibam mais que os pardos, eos pretos no Brasil dividem-se em duas Classes- os forros, e os cativosDos primeiros tem bastanteque temer os automatos fardados dePortugal; dos segundos nada receiam os Brasileiros. (Revérbero Constitucional Fluminense, n. 16, t. II, 10/9/1822)

A passagem acima é curiosa não somente pelo tom de defesa da autonomia brasileira. Indica também conflitos permanentes da quela sociedade Em primeiro lugar, aponta as rivalidades entre portugueses europeus e libertos, que já mencionamos terem provavelmente como razão fulcral as disputas no mercado de trabalho em formação na cidade, onde portugueses imigrantes pobres competiam com homens "de cor", sobretudo com os forros e/ou escravos de ganho e de aluguel. Esta rivalidade se agravava nos quadros da tropa, na qual tanto escravos e forros quanto imigrantes buscavam maior espaço para a autonomia. Além disso, revela com dareza a importância e a atenção dispensada aos movimentos da população parda e preta naqueles anos. Logo no mês seguinte, no dia 8, o Revérbero noticiava que Portugal não deveria tardar em reconhecer a nosssa autonomia não devendo mandar tropas para nos reduzir à escravidão, 
caso contrário ocorreria algo semelhante ao que ocorreu com a França com relação a São Domingos. Continuando, dizia querer esclare cer aos deputados constituintes lisboetas algo que eles não sabiam, "[que] os Escravos têm repartido o nosso ódio para com das: escusam portanto de estar nos ameaçando com este mal, nem mesmo de estar formando planos a este respeito: temam que o feitiço se não volte contra o feiticeiro". ${ }^{35}$

Ou seja, o articulista reconhecia que os escravos não eram pas sivos diante dos últimos acontecimentos, sabiam o que estava em questão naqueles dias. Os escravos e libertos participavam com igual intensidade na política do país e nos movimentos ocorridos na cida de, envidando efforços em favor de uns e contra outros. Na nota de n. 25, feita pelos redatores à "M emória sobre a Independência da América", publicada pelo jornal, falam que a independência do Bra sil era inevitável, apesar dos vaticánios do deputado Girão, português, que repetia que se isso acontecesse o pás seria colonizado por estrangeiros e os negros rebelar-seiam, como em São Domingos. Lembravam ainda que por três vezes as tropas européas haviam sido expulsas do Brasil e que Portugal deveria pagar logo 4\$000 contos de rés, dívida contraída quando a Corte veio para cá, agravada por terem ainda hipotecado a I lha da Madeira aos ingleses para fazerem guerra ao Brasil. Portanto, a única nação que poderia conquistar o Brasil seria a Inglaterra, a quem mais interessava o comércio do que a guerra

Se em 10/4/1822 o mesmo Revérbero ${ }^{36}$ anunciava a existência de batalhões de pardos no Rio de Janeiro em defesa da liberda de; depois da independência política consumada e dos laços rompidos com Portugal, a população "de cor" passou a lutar abertamente pela manutenção da liberdade É mais certo que pensassem nas conseqüências da "liberdade" para si, não propriamente no desejo de ver o Brasil definitivamente separado da Metrópole. Após 1822 houve um aumento expressivo do registro do número de fugas nos Códices da Polícia encontrados no Arquivo Nacional. Os escravos alistavam-se nos batalhões para lutarem na Guerra da Independência.

É necessário queVm cecom a brevidadepossível averigúe seJ oséBento Barbosa morador nesse Distrito éSnr. de um escravo pardo por nome Manoel, filho de uma escrava sua denomeM aria: que constater assenta do Praça voluntário no Regimento deArtilharia desta Corte, çomo liberto, fugindo a seu senhor ou seera conhedido por liberto (...). 
Casos como o do pardo Manoel pontilhavam a correspondência do chefe de Polícia com os comandantes de Distrito da cidade do Rio de Janeiro. Lutar na Guerra da Independência não foi privilégio dos escravos baianos. No Rio de Janeiro, de 1822 a 1824, sobretudo entre junho e setembro de 1824, fortes foram construídos para a defesa da cidade contra uma possível invasão portuguesa Se àquela altura a independência ia sendo consolidada com a paz no Nortee Nordeste e com os primeiros contatos para o reconhecimento da separação definitiva, sabiase, desde finais de 1823, dos planos efetivos de invasão portuguesa ao Rio de Janeiro. Portanto, nenhuma precaução era demasiada Para os escravos, trabalhar nas obras dessas fortificações, situadas em regiões fronteiriças, ${ }^{38}$ poderia significar a possibilidade da liberdade e de uma vida melhor: fugizse na calada da noite para o serviço nos fortes e, das obras dos fortes e dos senviços públicos para se aquilombarem. Ressaltese, então, que muitos escravos tinham esta esperança de forma efetiva, uma vez que alguns cativos baianos tinham conseguido a liberdade na luta contra os "portugueses". 39

Assim, há aspectos interessantes que devem ser observados na construção de uma nova interpretação do período. A Guerra da Independência não estava tão longe de ameaçar a Capital, não sendo apenas problema de províncias distantes. Se não houve combates "re ais" com o "inimigo externo", a ameaça e o medo dos lusos eram me nos efeivos que o pavor da luta interna, nas fronteras do próprio espaço urbano. Muitas dessas regiões abrigavam quilombos perigosos, como aquele de Iguaçu, podendo igualmente essas fortificações servirem de defesa contra os próprios "negros". Não é à toa que as autoridades vigiavam as tavernas, situadas justamente nessas regiões fronteiriças e de quilombos. Nelas havia uma intensa circulação e troca de idéas. Aí os quilombolas comerciavam suas mercadorias ${ }^{40} \mathrm{e}$ os marujos, cativos, libertos e desertores reuniam-se para jogar e be ber. ${ }^{41}$

De 1820 em diante, com tantas notícias que corriam pela cidade e com tanto se falar em liberdade, apertou-se o cerco a esses estabdecimentos. Foram obrigados a fechar às 8:00 da noite, exceto os dos arraiais e dos portos públicos, que deveriam cerrar as portas às 10:00 horas. Em 23 de novembro de 1821, um edital regulamentava os seus horários e as suas atividades ${ }^{42}$ Os distritos mais visados eram, entre outros, Pilar, I rajá, Inhaúma e Merity.43 O mais curioso é que a repressão ficava normalmente a cargo do brigadeiro 
Miguel Nunes Vidigal, possivelmente o mesmo truculento Vidigal do romance Memórias de um sargento de milídas ${ }^{44}$

Em 1823 e 1824, o intendente da Polícia da época, o nosso velho conhecido Estevão Ribeiro de Resende, incumbiu o mesmo Vidigal de perscrutar as ruas e as vielas atrás de papés e prodama ções "incendiárias" e de ajuntamentos perigosos de "negros". Muitos de tais documentos foram descobertos pela cidade, principalmente nas Freguesias urbanas ${ }^{45}$ Uma portaria de 26 de fevereiro e um de creto de 8 de março de 1824 procuraram coibir estes panfletos "insidiosos" e punir com rigor as desordens e os ajuntamentos. ${ }^{46}$

Em 3 de janeiro do ano seguinte, um edital tentava sanar a intranqüilidade pública por méo de 11 itens que visavam a controlar a população. ${ }^{47} \mathrm{Em}$ julho, reafirmou-se com mais veemência a nãoconcessão de licenças para tavernas, lojas e botequins que continuassem abertos ao público em horas indevidas, até mesmo se vendessem secos e molhados. ${ }^{48}$ Nesse mesmo mês, Clemente Ferreira França, secretário de Estado dos Negócios do Império, enviou ao corregedor do Civil uma ordem para que as tipografias mandassem todo o material que imprimissem para seu exame ${ }^{49}$ Tentava pôr limites à liberdade de imprensa No final do ano, em portaria de 5/ 11/1825, para concretizar ainda mais as medidas de repressão, esta beleceu comissários de Polícia nos distritos da Província do Rio de Janeiro. Por meio de uma estreita vigilância, controlava-se a popula ção e a onda de revoltas ia sendo contida até começar a crescer novamente, no ano seguinte

A imagem daqueles dias, na pena de ofícios, representações, cartas, leis, manifestos e outros papés oficiais, é bem diferente daquela de uma independência feita placidamente às margens do I piranga, sem sobressaltos para o Sudeste, principalmente para a Corte

A "cidade esconderijo"50 já era um fato no início do século XIX; abrigava escravos fugitivos que se movimentavam com desenvoltura e procuravam trilhar caminhos para a liberdade, igualmente entendida como direitos de autonomia Para os escravos, em um primeiro momento, o alento da alforria pode ter embalado noites de sono. Os grandes proprietários redamavam de ter que obedecer a decreto que os obrigava a fornecer 1/5 dos escravos que possuíssem para a guerra, ao passo que os escravos fugiam e se colocavam ao abrigo do comandante para fazer cumprir a lei. Não o faziam, evidentemente por patriotismo, mas suas atitudes alimentavam o imaginário 
do medo da rebelião e causavam pesadelos e preocupação ao Povo com "P" maiúsculo. Redamavam às autoridades sobre os seus direitos de propriedade, não desejando fornecer escravo algum, mesmo sob pena de acusação de não-fidelidade à causa nacional. O outro "povo", aquele com "p" minúsculo e aliado nos alistamentos, nos combates externos e na construção das fortificações, era uma ameaça porque tentava abrir espaços e construir no cotidiano os caminhos para a liberdade

Portanto, no intenso debate político sobre a independência, sobre a liberdade e a libertação do jugo da reescravização, os escra vos fizeram uma leitura própria dessas idéias e colocaram-na em prá tica. Quem sabe se baseados na concepção africana de liberdade ${ }^{51}$ não estariam, no caso da sua atuação na Corte, buscando um maior enrai zamento naquela sociedade, "nascendo" com a nova Nação e tentando conquistar um espaço no Estado em construção? Talvez a prova mais cabal seja o documento que Jaime Rodrigues encontrou no qual escravos solicitaram a sua liberdade em abaixo-assinado dirigido à Assembléia Constituinte de 1823.

Notas

1. Um balanço da historiografia sobre a independência e sobre os primeiros anos do Brasil independente pode ser encontrado em Ribeiro, 2000.

2. A forma como o contrato social foi pactuado entre o re e seus súditos foi estudada pormenorizadamente por Souza, 1998.

3. Para mais detal hes sobre o projeto do império luso-brasileiro e a independência do Brasil ver: Lyra, 1994.

4. Cf. contra Fragoso, 1992.

5. Alexandre, 1993, p. 583.

6. Mais tarde um pouco, com este racioćnio aprovaram o envio de tropas a Pernambuco, uma província como outra qualquer do império.

7. Projeto Apresentado em Cortes pelos Deputados de São Paulo para restabelecer os Negódios Políticos entre Brasil e Portugal, s/l., 1822, Seção de Manuscritos, B.N.

8. Alexandre, 1993, p. 611. A delegação paulista trazia instruções precisas da Junta de São Paulo; dela faziam parte Antônio Carlos, Feijó e Campos Vergueiro.

9. Idem, p. 614-617.

10. Idem, p. 621.

11. Idem, p. 622-623.

12. Idem, p. 589 (ligações da burguesia mercantil portuguesa com o Nordeste) e 624 (tensões entre parlamentares e burguesia mercantil).

13. Idem, p. 623. 
14. Idem, ibid.

15. A construção do Brasil como "corpo político autônomo" foi analisada por Souza, 1998.

16. Alexandre, 1993, p. 457.

17. Hobsbawn, 1990, p. 27.

18. Ver a este respeito: Alexandre, 1993b.

19. Esses "vivas" podem ser encontrados nas manifestações de rua do período, sobretudo naquelas que antecederam o que chamamos de indpendência do Brasil e abdicação. Para um exemplo, ver sobre as "Noites das Garrafadas": Traslado do Processo a que deram motivo os tumultos das garrafadas dos dias 13, 14 e 15 de março de 1831, Seção de Manuscritos, B.N.

20. Oposto ao Povo, com " $\mathrm{P}$ " maiúsculo, que era igual aos cidadãos, com todos os direitos.

21. A crítica à noção de resistência como algo que informava a vida de todos os escravos foi feita, entre outros, por Carvalho, 1998, e Reis, 1995/1996.

22. A forma como o direito natural foi compreendido em Portugal e as disputas ao redor das diferentes formas de conceber o direito podem ser encontradas nos livros de Hespanha: 1978, 1993 e 1997.

23. Os cidadãos passivos não possuíam os direitos políticos, apenas tinham direitos civis.

24. Nos Códices 323, vol. 6, e no 326, vol. 3, há alguns exemplos da maior vigilância e da preocupação excessiva das autoridades para com os escravos nesse momento.

25. Edital de 3/10/1821, José Paulo de Figueirôa Nabuco de Araújo, Legisação Brasileira ou Coleção Chronológica das Leis, Decretos, Resoluções de Consulta, Provisões, etc., etc., do Império do Brasil Desde o Ano de 1808 até 1831 Indusive Contendo: Além do que se Acha Publicado nas Melhores Coleçoes, para Mais de Duas Mil Peças I néditas Colligidas pelo Consel heiro J osé Paulo de Figueirôa Nabuco de Araújo. Rio de Janeiro: Typ. Imp. e Const. de J. Villeneuve e Comp, 1836, tomo 3, p. 228, A.N.

26. Portaria de 31/10/1821, José Paulo de Figueirôa Nabuco de Araújo, op. cit., tomo 3, p. 235, A.N.

27. Ofício do ministro do Reino e Estrangeiros, Francisco José Vieira, ao intendentegeral da Polícia. IJJ 1179 Ministério do Reino e Estrangeiros. 1821-1822, 23/10/ 1821, p. 32, A.N. (proibia os "pretos" de andarem mascarados).

28. Ofício dirigido por João Ignácio da Cunha, intendentegeral da Polícia, ao ministro de Estado da Guerra, Carlos Frederico de Caula. Códice 323 (Correspondência da Polída aos Ministros de Estado, Juízes de Crime, Câmara, đc.). 6 (1820-1822), 8/ 12/1821, pp. 103 a 105, A.N.

29. Nesse ano foi remetida a José Bonifácio uma memória tratando da segurança das es tradas. O autor foi o tesoureiro do Tesouro Público por quatro anos; oferecia como testemunhas de sua boa conduta J oaquim Gonçal ves Ledo e o coronel Manoel Ferreira Araújo Guimarães, este último lente da Real Academia Militar. Felisberto Ignácio Januário. Memória sobre as Estradas infestadas de Salteadores e Ciganos. In: Códice 807, 1822, vol. 7, A.N.

30. Ofício de José Bonifácio de Andrada e Silva, ministro e secretário dos Negócios do Reino, ao intendentegeral da Polícia interino. IJ 1179 Ministéio do Reino e Estrangeiros 1821-1822, 2/2/1822, p. 161, A.N.

31. Registro do Gabinete de J osé Bonifádio no 8 (Códice 753). In: Publicações do Arquivo Nacional. Rio de Janeiro: Officinas Graphicas do Arquivo Nacional, 1916, A.N. 
32. Corréo do Rio de Janeiro, № 13, 24/4/1822, B.N. Corria uma notícia de que os milicianos europeus atacariam os brasileiros e projetavam a liberdade dos escravos. Conferir também: Lembranças e Apontamentos Rio de Janeiro: 10 de abril de 1822, Coleção Lagosiana ou Coleção Lagos, Seção de Obras Gerais, B.N.

33. Ofício de José Bonifácio de Andrada e Silva, ministro e secretário de Estado dos $\mathrm{Ne}$ gócios do Reino, para o intendentegeral da Polícia. IJJ 1167 Ministério do Reino e Estranger ros. 1822, 5/8/1822, A.N.

34. Revérbero Constitudional Fluminense, № 16, tomo II, 10/9/1822.

35. Revérbero Constitucional Fluminense, $\mathrm{n}$ ㅇ 20, tomo II, 8/10/1822.

36. Revérbero Constitucional Fluminense, $\mathrm{n}$ - 23, tomo I, 10/4/1822.

37. Códice 326. Ofício ao comandante de Irajá, 13/8/1824, A.N.

38. Essas fortificações foram construídas em regiões fronteiriças da Corte: Paraty. Sepetiba, Tagoahy, Campo Grande, Guaratiba, Jacarepaguá, Marapicu, Pilar, Engenho Velho, Pedregulho (Irajá), Inhaúma, Aguassu (I guaçu), Merity, Lagoa, Jacoatinga, São Gonçalo, Macacu, Tapacorá, Macaé, Cabo Frio, entre outras.

39. Acredito que não devamos igualmente descartar a hipótese de que pudesse passar pela imaginação dos escravos que, estando em regiões fronteiriças - forte e quilombos -, pudessem também auxiliar os portugueses, ganhando em troca a alforria.

40. Flávio dos Santos Gomes. Histórias de Quilombolas Mocambos e Comuni dades de Senzalas no Rio de Janéro - Século XIX. 3o Prêmio Arquivo Nacional. Rio de Janeiro: Arquivo Nacional, 1995.

41. Conferir documentos de 3/2/1820, p. 62, verso; 29/2/1820, p. 64; 20/1/1821, p. 89, verso, e 90; 23/1/1821, p. 91, frente e verso. Códice 326 (Ofícos expedidos pela Polícia para o Governo de Armas da Corte, Patentes Militares e Ordenanças, vol. 3 (1818-1820), A.N.

42. Ofício do ministro do Reino e Estrangeiros, Francisco J osé Vieira, ao intendente da Polícia. IJJ 1179 Ministério do Reino e Estrangeiros. 1821-1822, 23/11/1821, p. 68, frente e verso, A.N. (encaminhava um edital sobre o funcionamento das tavernas, a fim de evitar desordens e ajuntamentos).

43. Uma vasta documentação sobre as tavernas como locais perigosos de ajuntamentos e de coação ao seu funcionamento pode ser encontrada nos Códices 326, vol. 3 (18181822), A.N.; 327, vol. 1 (1815-1826), A.N.; IJJ 1179 Ministério do Réno e Estrangeiros 1821-1822, A.N.; IJJ 1167 Ministério do Reino e Estrangeiros. 1822, A.N.

44. Joaquim Manuel de Macedo, Memórias de um sargento de milícias Rio de Janeiro: Edições de Ouro, s/d.

45. Ofício do intendentegeral da Polícia, Estevão Ribeiro de Resende, ao brigadeiro Miguel Nunes Vidigal. Códice 327 (Registro de Ofícios da Polída ao Comandante Real e depois Imperial da Guarda da Polícia). 1815-1831, 2 vols., vol. 1(18151826), 7/8/1823, p. 109. Neste Códice e no 326 há notícias de papéis e proclamações incendiárias, bem como de manuscritos espal hados pelas portas das igrejas da cidade.

46. Portaria de $26 / 2 / 1824$, José Paulo de Figueirôa Nabuco de Araújo, op. cit., tomo 4 , p. 217, A.N.; Decreto de 8/3/1824, José Paulo de Figueirôa Nabuco de Araújo, op. cit., tomo 4, p. 221, A.N.

47. Edital de 3/1/1825, José Paulo de Figuerôa Nabuco de Araújo, op. cit., tomo 5, p. 1 , A.N. 
48. Portaria de $20 / 7 / 1825$, José Paulo de Figueirôa Nabuco de Araújo, op. cit., tomo 5 , p. 118, A.N

49. Aviso de Clemente Ferreira França ao corregedor do Civil. IJ 196 Corte Registro de Avisos 11 dezembro de 1824-30 de julho de 1825, 21/7/1825, Relação 29, Parte 14, Livro V, p. 180, frente, A.N.

50. Termo usado por Chalhoub, 1990.

51. A liberdade era relacionada ao sentimento de "pertencer", nascer e crescer em uma comunidade; ser membro de uma linhagem.

\section{Referênciasbibliográficas}

ALENCAST RO, L. F. Lecommerce des vivants traite d'esdavages et 'pax lusitana' dans I' Atlantique Sud. 1985-86. 2v. Tese (doutorado) Université de Paris $X$, Paris.

ALENCASTRO, L. F. O trato dos viventes formação do Brasil no Atlântico Sul. São Paulo: Cia das Letras, 2000.

ALEXANDRE, V. A desagregação do império: Portuga e o reconhecimento do Estado brasileiro (1824-1826). AnáliseSocial, Lisboa, v. 28, n. 121, 1993b.

ALEXANDRE, V. Os sentidos do Império: questão nacional e colonial na crise do antigo regime português. Porto: Afrontamento, 1993a.

CARVALHO, M. Liberdade rotinas e rupturas do escravismo; Redife, 1822-1850. Recife UFPE, 1998.

CHALHOUB, S. Vis̃̃es da liberdade São Paulo: Cia das Letras, 1990.

DIAS, M. O. L. S. A interiorização da metrópole In: MotA, C. G. 1822: dimensões São Paulo: Perspectiva, 1972.

FRAGOSO, J. L. R. Homens degrossa aventura: acumulação ehierarquia na praça mercantil do Rio de Janeiro (1790- 1830). Rio de Janeiro: Arquivo Nacional, 1992.

Franco, M. S. C. As idéas estão no lugar. São Paulo: Brasiliense, 1976.

GORENSTEIN, R. Comércio e política: o enraizamento de interesses mercantis portugueses no Rio de Janeiro (1808-1830). In: MARTINHO, L. M. Negociantesecai xérosna sociedadeda independênia. Rio de Janeiro: Departamento Geral de Documentação e Informação Cultural, 1993. 
GRINBERG, K. O fiador dos brasileiros cidadania, escravidão e direito divil no tempo de Antônio Pereira Rebouças 2000. Tese (doutora do) - Departamento de História, Universidade Federal Fluminense, Niterói.

HESPANHA, A. M. A história do direito na história social. Lisboa: Livros Horizonte, 1978.

HESPANHA, A M. (Org.). Justiça elitigiosidade história e prospectiva. Lisboa: Fundação Calouste Gulbenkian, 1993.

HESPANHA, A M. Panorama histórico da cultura jurídica europêa. Lis boa: Publicações Europa-América, 1997.

HOBSBAWN, E. Nação e nacionalismo desde 1780: programa, mito e realidades. Trad. Maria Célia Paoli eAnna Maria Quirino. São Paur Io: Cia das Letras, 1990.

HOLANDA, S. B. Herança colonia: sua desagregação. In: HolandA, S. B. (Org.). História geral da divilização brasileira. São Paulo; Rio de Janeiro: Dife, 1976. v.1 t.2.

LENHARO, A. As tropas da moderaçãa. São Paulo: Símbolo, 1979.

LYRA, M. L. V. A ruptura da unidadeluso-brasileira: o império braślico. In: LYRA, M. L. V. A utopia do poderoso império. Rio deJaneiro: Sette Letras, 1994.

MARTINHO, L. M. Caixeiros e pés-descalços: conflitos e tensões em um meio urbano em desenvolvimento. In: Martinho, L. M. Ne gociantes e cai xéros na sociedade da independêndia. Rio de Janeiro: Departamento Geral de Documentação e Informação Cultural, 1993.

NOVAIS, F. Portugal e Brasil na orise do antigo sistema colonial (17771808). São Paulo: Hucitec, 1979.

PENA, E. S. Pajens da Casa Imperial: jurisconsultos e escravidão no Brasil do século XIX. 1998. 409f. Tese (doutorado) - Instituto de Filosofia e Ciências Humanas, Universidade Estadual de Campinas, Campinas.

PRADO JÚNIOR, C. Evolução política do Brasi eautrosestudos 10. ed. São Paulo: Brasiliense, 1977. 
PRADO JÚNIOR, C. Formação do Brasil contemporânea 15. ed. São Paulo: Brasiliense, 1977.

REIS, J. J. Quilombos erevoltas escravas no Brasil. Revista usp, São Par lo, n. 28, p. 14-39, dez/fev. 1995/1996.

RIBEIRO, G. S. Os portugueses na formação da nação brasileira o de bate historiográfico desde 1836. Ler Hisória, Lisboa, n. 38, 2000.

RODRIGUES, J. Liberdade, humanidade e propriedade os escravos ea Assembléa Constituinte de 1823. Revista do Instituto de Estudos Brasilèros da Usp, São Paulo, v. 39, p. 159-167, 1995.

SODRÉ, N. W. As razões da independênda. Rio de Janeiro: Civilização brasileira, 1965.

SODRÉ, N. W. Fơrmação histórica do Brasil. São Paulo: Brasiliense, 1968.

SOUZA, I. L. C. A pátria carcada: o Brasil como corpo político autônomo. São Paulo: UNESP, 1998. 